\title{
Patrick Wald Lasowski, Le Traité du transport amoureux
}

Valentina Ponzetto

\section{Q OpenEdition}

1 Journals

\section{Edizione digitale}

URL: http://journals.openedition.org/studifrancesi/30267

DOI: $10.4000 /$ studifrancesi.30267

ISSN: 2427-5856

\section{Editore}

Rosenberg \& Sellier

\section{Edizione cartacea}

Data di pubblicazione: 1 avril 2006

Paginazione: 153

ISSN: 0039-2944

\section{Notizia bibliografica digitale}

Valentina Ponzetto, «Patrick Wald Lasowski, Le Traité du transport amoureux», Studi Francesi [Online], $148(X L X \mid$ I) | 2006, online dal 30 novembre 2015, consultato il 21 avril 2021. URL: http:// journals.openedition.org/studifrancesi/30267 ; DOI: https://doi.org/10.4000/studifrancesi.30267

Questo documento è stato generato automaticamente il 21 avril 2021.

\section{(c) (i) (9)}

Studi Francesi è distribuita con Licenza Creative Commons Attribuzione - Non commerciale - Non opere derivate 4.0 Internazionale. 


\title{
Patrick Wald Lasowski, Le Traité du transport amoureux
}

\author{
Valentina Ponzetto
}

\section{NOTIZIA}

PATRICK WALD LASOWSKI, Le Traité du transport amoureux, Paris, Gallimard, («Le promeneur»), 2004, pp. 97.

1 Più che un vero e proprio trattato, il Traité du trans-port amoureux è un curioso viaggio letterario, che conduce un lettore divertito e sedotto nel brillante e turbinoso mondo dei trasporti settecenteschi. Il trasporto è infatti il solo filo conduttore di questo libro, in cui Patrick Wald Lasowski riprende con successo la formula del precedente Traité des mouches secrètes, qui spinto alle sue estreme conseguenze: la polisemia del termine, su cui già maliziosamente giocano gli autori settecenteschi, è colta in ogni sua occorrenza e sfumatura, in un funambolico esercizio di virtuosismo che stuzzica la curiosità catalogando ambiguità, equivoci, stranezze, sempre in bilico fra senso letterale e figurato. Cos'è del resto la metafora, ricorda l'autore, se non «un transport d'un mot propre à un sens figuré»? Ecco allora pittoreschi e ricchi cataloghi di mezzi di locomozione - coches, voitures, diligences, chaises à porteurs, carrosses, phaétons avventure di viaggio, storie di cocchieri, mescolarsi e intrecciarsi con ogni sorta di trasporto delle passioni e dei sensi.

Dagli uni agli altri, del resto, il passo è breve, praticamente impercettibile. In tutto il romanzo del Settecento, da Manon Lescaut alla Nouvelle Héloïse dalla Vie de Marianne a Point de lendemain, gli incontri di viaggio fanno scoccare improvvise passioni, gli amanti sono gettati in un turbine di partenze, fughe, inseguimenti, le carrozze stesse si trasformano, spesso e volentieri, in alcove ambulanti. Gli spostamenti precipitano la dinamica amorosa, i sobbalzi delle strade sconnesse accompagnano altre, più intime scosse, le donne amano «échouer décemment dans un vis-à-vis». Carrosse e caresse fanno quasi tutt'uno. Gli eroi libertini, maestri del trasporto, sanno calibrare e piegare ai loro 
voleri l'intensità degli ardori, la durata di un tragitto, la complicità del cocchiere. Su tutti domina Casanova, rapidissimo a cogliere i vantaggi strategici di una carrozza troppo piccola, o dei timori improvvisi di una viaggiatrice. «Voyageur par excellence, parfait séducteur», il veneziano incarna, per Patrick Wald Lasowski, «le transport en personne», e stralci delle sue avventure punteggiano da un capo all'altro questo Traité $d u$ transport amoureux, affiorando di tanto in tanto come un leit-motiv.

Il saggio è infatti frammentario, formato di brevi o brevissimi episodi giustapposti, che a volte hanno quasi il carattere di un appunto. Piccoli tocchi, scene fugaci, raccontate con tono leggero, brioso, si susseguono con ritmo rapidissimo, capriccioso, accostate talora per analogia, talora per contrasto. Il romanzo vi confina con la lessicografia, la cronaca giudiziaria, la memorialistica. Ancora una volta Wald Lasowski propone la sua visione di un XVIII secolo in cui l'alto e il basso, il galante e l'osceno, il mondo dorato della nobiltà e quello sordido delle prostitute e dei cocchieri si fondono inestricabilmente. Dagli appassionati trasporti di Saint-Preux alle posizioni erotiche comuni o ricercate, come la diligence, la chaise à porteurs o faire le postillon, dalle sensuali fate di La Morlière che insegnano allo sprovveduto principe Angola «les avantages de reconduire», alle ragazze di strada condotte alla Salpetrière su una carretta scoperta, il quadro è ampio e variegato. Senza offrire materia veramente nuova, l'autore ha però il pregio di presentarla nella maniera più deliziosa possibile. Così non si dovrà cercare in questo libro una tesi precisa, ma un piacere rapido, un divertissement disimpegnato per amatori di letteratura libertina. 